\title{
1. Introduction and synthesis
}

\section{Andrés Solimano}

\subsection{INTRODUCTION}

Economic growth is the main source of wealth creation and material welfare to the population. In fact, as an indication of the centrality of the process of wealth creation in economics, Adam Smith entitled his main contribution to economic science, An Inquiry on the Causes of the Wealth of Nations, where he investigated the various causes that lead to wealth creation as opposed to the dilapidation of material wealth. The importance of economic growth cannot be overstated. Even relatively small differences in annual growth rates in Gross Domestic Product among countries, when they accumulate over time, can generate large differences in living standards for a country's population. Getting the right (or wrong) policy mix for growth can have far-reaching consequences for the welfare levels (or misery) of its citizens. Nevertheless, in spite of the importance of the topic, our knowledge of the subject is far from complete. The causes that initiate, propagate or stop economic growth are numerous in practice and vary across nations and time. Understanding the causes of growth has important practical implications for the personal fortunes of many people around the world.

Economic growth theory has focused on the relative role of factor accumulation (labor, physical and human capital, natural resources) and productivity growth (due to new knowledge and changes in efficiency with which productive factors are combined) in explaining output growth. This approach is often referred as the 'mechanics of growth' in which factor accumulation and TFP growth constitute the 'proximate' sources of growth on the supply side. In the search of 'ultimate' factors that drive growth we find a long list of variables: incentives, institutions, macroeconomic and political stability, terms of trade and other external shocks, the quality of the political regime, the respect given to property rights, the degree of distributive conflict, geography and others. Pinpointing the specific importance of each of these factors in a given country and time period is one of the tasks of growth analysis.

Two trends have dominated growth economics since the mid-1980s until today: the rise of the endogenous growth theory and the ample use of cross- 
section growth regressions to test the various propositions of the new growth theory and the effects of macro, trade, financial policies, education and so on, on growth. Most of this analysis is aggregative in nature and focuses on steady-state dynamics. In a sense, this literature has downplayed the concrete factors in specific country experiences that create an impulse to wealth creation and the factors that maintain or stop that impulse. The anatomy of growth at sector and micro levels probably shows a wide variety of growth impulses and contractions operating across the economy with various net effects at aggregate level. Attempted generality (supposedly achieved by cross-section regressions of a large number of countries) is often sought at the cost of missing out the rich concrete experience of countries. Their experiences illuminate concrete factors which boost or impede growth, although those experiences may not lend themselves, in many instances, to easy and mechanical generalizations of the grand factors that drive economic growth.

The global growth experience of the last two to three decades of the twentieth century shows a wide variety of growth paths over time and across countries. This is in contrast with the background of growth economics developed in the 1950s and 1960s that viewed growth as a smooth process around a well-defined trend. Recent empirical evidence shows that growth tends to be a volatile process with little serial correlation in growth rates over time around virtually no trend: past growth is often a poor predictor of future growth. This stylized fact about growth rates is particularly applicable to developing countries and Latin America in particular where growth is more unstable than the growth process of rich industrialized countries (that is the OECD countries).

Models that assume a smooth growth path around a certain mean rate often fail to capture this variety and variability in growth rates. These models are a better approximation for explaining long-run growth trends in countries such as the United States for example where during most of the twentieth century, the economy grew at a smooth rate near 2 per cent per year (except during the Great Depression of the 1930s and the stagflation of the 1970s) or Europe between the late 1940s and early 1970s, during the so-called golden age of capitalism (growth was unstable in the 1914-45 period as Europe witnessed two world wars, high inflation, macroeconomic instability, depression and acute political conflict). In the developing world, global economic performance in the 1980s, 1990s and early 2000s has been affected by shocks and policies that include the debt crises of the 1980s, the reforms of the 1990s, the effect of globalization and financial volatility in the second half of the 1990s. In this period we have seen both success growth stories (that is China, India, Ireland, Chile, Botswana and a few others, although not too many) along with several stories of growth failure, stagnation and even growth 
implosions (Venezuela, Brazil, Mexico, Argentina after 1980, many SubSaharan economies, Russia and former soviet republics during most of the 1990s and others). Much can be learned from these cases in terms of the factors that produce growth, stagnation or growth collapse.

\subsection{THE GROWTH RECORD OF LATIN AMERICA}

The focus of this book is on the economic growth performance of Latin America in the last two to four decades of the twentieth century. A main message of this volume is that the growth performance of Latin America in the 1980s and 1990s was, on the whole, modest and plagued by cycles that made economic growth also a volatile process. Growth decelerated in most Latin American and Caribbean countries after 1980 with the exception of Chile and Dominican Republic. Average annual growth rates in GDP per capita for the region went down from 3 per cent in 1960-80 to 0.5 per cent in 1980-2002. In addition, the volatility of growth increased in the 1980s and 1990s as compared to previous decades (see Chapter 2 in this volume). Economic growth recovered in the 1990s in Latin America with respect to the 1980s (the decade of the debt crises) although that recovery was again interrupted by the effects of the Asian crises of 1997-8 that sent the region back to a half-decade of sluggish growth. The new hopes for lasting prosperity following the adoption of market-oriented reforms helped by a greater availability of external finance, have been largely disappointed in the critical field of economic growth.

It is apparent that the Latin American region had serious difficulties in adjusting to the global shocks of the last two decades such as the debt crises of the 1980s, the recurrent cycles in capital flows and commodity prices, the various financial crises of the 1990s and early 2000s (Mexico 1994, Asia 1997-8, Russia 1998 and others). At country level, the Latin American region displays also a wide variety of growth experiences in the last four decades. The two economies that grew the fastest in 1960-80, under import substitution and state-dirigisme, Mexico and Brazil, suffered a protracted growth slowdown in the post-1980 period. Incidentally, these are the two largest economies of the region. In turn, two other resource-rich economies of the region, Argentina and Venezuela, experienced sharp growth cycles in the 1980s, 1990s and early 2000s within an overall trend of economic decline with respect to a sustained growth trend. In contrast, Chile managed to grow at more than 7 per cent per year during 1986-97, although growth slowed down for years afterwards, to recover again in 2004-2005 following a boom in copper prices. Also, the Dominican Republic grew very rapidly between 1992 and 2000 although it fell into a crisis in 2002-3. 
Other economies of the region suffered various growth cycles but without a noticeable sustained upward trend in growth rates. Macroeconomic instability, inflation, exchange rate volatility, fiscal deficits and external vulnerability have been characteristics of Latin America. The reforms of the 1990s in the region tried to tackle macroeconomic stabilization, the endemic problems of instability and limited growth through policies of external openness, deregulation and privatization. These policies contributed to restore more acceptable levels of macro stability and led to once-and-for-all productivity gains after major distortions were eliminated but their impact on economic growth was neither spectacular nor sustained over time. Investment and savings ratios did not increase significantly and total factor productivity did not accelerate much as we shall see in the different studies included in this book. Public investment declined for most of the 1980s and 1990s and the response of private investment did not compensate for the cut in public investment in most countries of the region (Chile, again, being the exception).

The 'proximate sources' supporting steady growth were simply not there in most of Latin America. Moreover, the region has developed unevenly and conflictive social structure and the quality of its institutions often conspires against steady economic growth. Poverty, inequality and in some countries the exclusion of ethnic groups often lead to social polarization and political instability. In addition, indices of quality of institutions and the costs of doing business put Latin American countries in a modest place in these international rankings. Social consensus is often hard to reach and economic policymaking becomes a difficult process. As a consequence of all this, the socio-political structure of Latin American societies is often not very supportive for capital formation, innovation and growth. Unfortunately the reforms inspired in the Washington consensus have not succeeded in tackling the unequal social structure of the region and its institutions.

In the last four decades or so, Latin American countries have tried various economic models such as import substitution and state dirigisme, socialism, populism and free market reform to solve its endemic economic and social problems and spur economic growth. The political correlates of the economic models have included right-wing dictatorships mainly in the southern cone in the 1970 s and part of the 1980s, left-wing governments and various types of democratic and semi-democratic regimes in the 1990s and early 2000s. The outcomes of these experiments has varied depending upon countries and time periods but the robust result is that lasting and sustained growth and prosperity has remained elusive for most of the region as a whole although episodes of growth and prosperity were observed in some individual countries. In some countries those episodes of growth lasted around a decade or more. In turn, relatively long episodes of stagnation and decline are not uncommon in the Latin American region. 


\subsection{MAIN QUESTIONS}

The growth studies of this volume document and analyze the growth performance of various countries in three sub-regions of Latin America: the Southern Cone and Brazil; the Andean countries; Central America and Mexico. The studies in this volume try to ascertain empirically the main determinants of output growth highlighting also the factors that encourage growth and the elements that can impede it. The questions that the contributions of this volume address can be synthesized in the following:

- What has been the growth performance of Latin America in the last four decades, particularly in the 1980s and 1990s following the adoption of market-oriented reforms?

- What has been the contribution of factor accumulation and productivity growth to GDP growth in the different countries and sub-regions of Latin America?

- What is the role of economic shocks, macroeconomic policies and social and institutional structures in explaining the growth performance of the region?

- What starts a growth process? What sustains it? Why can a growth boom run out of steam? Can we provide examples of various growth cycles in Latin America?

- How persistent can a growth boom be? or a growth collapse? Can economic stagnation be a persistent feature in countries of Latin America?

- What is the impact of political economy considerations on growth, in conditions of inequality and through poor quality institutions?

- What is the impact of competitiveness, the trade regime, fiscal policy, education, inequality, economic policy and political instability on the rate of economic growth?

\subsection{REGIONAL COUNTRY STUDIES}

This book is organized into seven chapters, including this Introduction. Chapter 2 and Chapter 7 are regional growth studies and Chapters 3 to 6 comprise sub-regional growth analysis. The sub-regional growth studies refer to: (1) the 'Southern Cone' composed of Argentina, Brazil, Chile, Paraguay and Uruguay; (2) the Andean countries comprising Bolivia, Colombia, Ecuador, Peru and Venezuela and (3) Mexico and Central America including the Dominican Republic, El Salvador, Guatemala, Honduras, Mexico, Nicaragua and Panama. Most chapters cover the period running roughly from 1960 to 
2000 and their methodological approach is a mix of the sources of growth accounting model that separates the roles of factor accumulation and total productivity growth in explaining growth patterns, complemented with a structural approach of the 'ultimate' determinants of growth as specified by the different authors for their specific set of countries.

The book also tries to identify, at a regional level, patterns and cycles of growth, detecting episodes of rapid growth, of the collapse of growth (growth crises) and stagnation. A common theme across the different chapters is the impact of external shocks, domestic policies, structural reform and the underlying economic and political structure on the mean rate and variability of growth rates.

Chapter 2 by Andrés Solimano and Raimundo Soto considers 12 Latin American and Caribbean economies (Argentina, Bolivia, Brazil, Colombia, Chile, Costa Rica, Ecuador, Mexico, Peru, the Dominican Republic, Uruguay and Venezuela) in the period 1960-2002. The chapter presents several stylized facts of the growth performance of the 12 countries in 1960-80 compared with 1980-2002, showing that the distribution of growth rates of 1980-2002 exhibits a lower mean and higher standard deviation than the distribution of growth rates in the period 1960-80. The chapter also shows that there is great heterogeneity in growth performance across countries and over time in Latin America.

Also there is a change in the countries that were growing rapidly before and after 1980. Under import substitution strategies, Brazil and Mexico were fast growers before 1980. In contrast, under market-oriented policies, Chile and the Dominican Republic were fast growers after 1980. The chapter performs growth decompositions to assess the role of factor accumulation versus total factor productivity growth in explaining growth in the region; in general total factor productivity (TFP) growth (also reflecting cyclical elements) explain most of the variation in growth rates between the 1960s and 1970s and the 1980s and 1990s. The authors also show that in the post-1980 period, public investment has been more volatile than private investment in Latin America and that the reduction in public investment in the last two decades has not been compensated by an offsetting increase in private investment (except in Chile).

The chapter also focuses on the dynamics of growth in time spans of one to two decades for the group of 12 Latin American economies compared to a reference (or control group) outside the region, identifying episodes of rapid growth and of growth crises that last between five to ten years. In trying to explain the behavior of TFP growth, the chapter finds a high correlation between various measures of macro stability and TFP growth but no persistent correlation between external shocks and TFP growth.

Chapter 3 by Juan Blyde and Eduardo Fernández-Arias, looks at the growth record of Argentina, Brazil, Chile, Paraguay and Uruguay (referred as the 
'Southern Cone' countries, SC) in the 1960-2000 period. The chapter evaluates their growth performance taking as a benchmark a sample of 68 countries, of which 15 are from Latin America and 53 from the rest of the world (20 of them belong to developing countries). Southern Cone countries exhibited medium to strong growth in the 1960s and 1970s, deceleration in the 1980s, and recovery in the 1990s until the Asian crisis and then a growth slowdown or crisis (in Argentina and Uruguay growth collapsed following serious exchange rate and financial crises in each of the two countries in the early 2000s). Since 2003 Argentina, and Uruguay started a strong recovery. Argentina, Chile and Uruguay performed best in the 1990s (up to 1998) whereas Brazil and Paraguay saw better times in the 1970s. Brazil, for example, went from high to low growth during the 1960-2000 period and Chile followed the opposite path, going from moderate average growth in the 1960s and 1970s to faster average growth in 1980-2000 (although punctuated by growth cycles of different intensity). On average, the SC group grew slower than the rest of the world in the period 1960-2000 and experienced higher instability in growth rates than the overall sample of 68 countries.

The growth experience of the southern cone countries confirms our previous observation on the lack of correlation between growth rates over time that characterizes the growth process in many developing countries. The lagging growth performance of the SC group in recent decades is reflected in lack of convergence of per capita income with the rest of the world. The sources of growth calculation for the SC countries show that TFP growth is key to explaining the variability of GDP per capita growth in the sample period. Also the lack of TFP growth, except in Chile, accounts for most of the slower growth of the Southern Cone countries relative to the rest of the world. However, TFP growth is higher in the SC group than in the rest of Latin America, largely because of the weak growth in TFP of the rest of the region. The authors estimate a panel model and find that the degree of external openness and the quality of institutions are the main determinants of the growth in total factor productivity growth. Also the authors find that the share of imports of machinery and equipment in GDP, as a proxy for technology diffusion, is also an important determinant of TFP growth, a finding similar to the one found in Central America by Agosin and Machado in Chapter 5.

Chapter 4, by Claudio Aravena, André Hofman and Andrés Solimano, explores economic growth in the Andean countries (Bolivia, Colombia, Ecuador, Peru and Venezuela) for the whole twentieth century and for the 1950-2002 period. A main focus of the chapter is to distinguish between the effect of economic determinants and the impact of governance-related factors in explaining economic growth in the Andean region. In a long-run perspective, the data shows that the Andean countries grew faster in the first half of the twentieth century than in the second with a marked deceleration in growth 
rates after the mid-1970s. This trend was particularly noticeable in Venezuela, a rapid grower from the 1920 s to the 1970 s. In contrast, Colombia experienced a less severe decline in GDP and productivity growth with respect to the rest of the world, although since the mid-1990s growth slowed down. The chapter performs a source-of-growth decomposition between factor accumulation (labor, capital and land, adjusting for the quality of the factors of production) and total productivity growth for the period 1950 to 2002 and various sub-periods. The sources-of-growth analysis show a declining trend in TFP growth since 1973 when compared to the 1950-73 period. For 19502002 the average annual rate of TFP growth was below 1 per cent. Colombia experienced the highest TFP growth and Peru the lowest in this period. The chapter complements the sources of growth analysis with estimates of empirical growth equations using panel regressions for the five countries in the period 1950-2002. The analysis considers the effects of a set of economic and governance factors on growth such as initial per capita GDP, the investment ratio, inflation, exchange rate variability, degree of external openness, the ratio of government consumption on GDP, the type of political regime and degree of political instability. The empirical analysis shows that conditional convergence holds in the sample period, the investment ratio and the degree of external openness have a significant positive effect on GDP growth, and inflation has a negative effect on growth. Regarding governance variables the chapter finds that political instability (measured as frequency of presidential crises) has a negative effect on growth and democracy (with a lag) has a positive effect on growth, after controlling for other determinants of growth. Then growth regressions are run for each Andean country. The estimates tend to confirm the previous results on the effects of economic factors on growth but finds insignificant effects for the political regime variable on the growth rate of GDP.

Chapter 5, by Manuel Agosín and Roberto Machado, studies the process of economic growth in Costa Rica, El Salvador, Guatemala, Honduras, Nicaragua, Panama and the Dominican Republic in the period 1960-2000. The average income per capita level of the group is below U\$1500, and they specialize in tropical products, light manufacturing and tourism, and suffered the effects of the oil shocks of the 1970s, the debt crises of the 1980s and the financial instability of the second half of the 1990s and early 2000s. In the 1980s Nicaragua, El Salvador and Guatemala also experienced civil wars. In addition, several of these economies suffered natural disasters such as earthquakes and hurricanes that led to a loss of human life and the destruction of physical assets. They all started economic reforms in the early to mid-1990s. The growth performance of the group in the last 25 years has been moderate with little absolute convergence in per capita income to the levels of advanced countries; moreover, there is a variety in the growth performance of 
countries within the Central America group. Nicaragua has been a faltering economy since the 1980s although experiencing a modest and fragile recovery in the 1990s. In contrast, Costa Rica, the Dominican Republic, and Panama have had a better growth performance in this period.

The chapter identifies both 'proximate and ultimate' determinants of economic growth, highlighting the role of natural resources and history, integration to the world economy and institutions, in explaining growth patterns in Central America. A growth accounting exercise correcting for changes in quality of labor and capital inputs shows that around 85 per cent of total output growth in the 1991-99 period is due to capital accumulation and the rest to TFP growth. The results also show different contributions of TFP growth to GDP expansion through the seven countries with a higher contribution in Costa Rica, the Dominican Republic and El Salvador and a lower contribution in the other countries. In Nicaragua, TFP growth was virtually zero in that period. In general, physical capital accumulation was low in Central America although advances were made in the education area in the 1990s. The chapter also estimates a multi-equation model in which growth of GDP, investment in machinery and equipment; human capital and the degree of institutional development (rule of law) are simultaneously determined. The model is estimated with panel data of seven countries for 1971-2000. A strong effect is found for investment in machinery and equipment as a prime determinant of GDP growth. The degree of external openness, capital inflows and financial deepening, affect growth. The rule of law variable has a significant effect on GDP growth and on investment in machinery and equipment. Also the authors emphasize the double causality between growth, education and institutional development, noting that higher GDP growth and better education improve the rule of law.

Chapter 6 by Jaime Ros examines growth constraints in northern Latin America (NLA) namely Mexico and Central America (the same set of countries of Chapter 5 besides Mexico). The author notes the importance of tourism and export processing zones as new sources of growth in these countries. He also examines the recovery of growth in the 1990s in NLA following internal reforms, macroeconomic stabilization, increased US growth and the end of the armed conflict in El Salvador, Nicaragua and Guatemala. The author also explores the main factors affecting competitiveness and growth in the NLA countries such as the real exchange rate, the macroeconomic environment and the business climate. Ros also identifies some key constraints for growth in the NLA group: lagging competitiveness, inequality in income distribution, dependence on commodity exports with volatile prices in international markets, limited internal linkages and the weak productivity effects of newly dynamic export products. Using catching-up growth models to project potential growth and income convergence of the NLA countries the 
corresponding simulations do not yield very encouraging results for the medium run in those two dimensions (growth potential and convergence in income per capita levels). Finally the author provides calculations of required investment ratios, required export growth and savings gaps for the group of northern Latin American countries.

Chapter 7 by Mario Gutiérrez produces evidence about the contribution of the level and composition of investment and other sources to the growth process of Latin America during the period 1960-2002. The combined growth accounting and regression analysis used data for the six largest Latin American countries: Argentina, Brazil, Chile, Colombia, Mexico and Venezuela. These countries produce nearly 90 per cent of Latin America's GDP. Alternative growth accounting methodologies were used to measure the contributions of the sources of growth to GDP growth in this period. The study also provides evidence of the effects of investments in machinery and equipment and construction, and the effects of private and public investment on per capita GDP growth.

The research found evidence of the primary role played by total factor productivity in explaining the difference between fast and slow growth experiences. Extending the traditional growth accounting approach did not change this conclusion. It also found that investment in machinery and equipment, and private investment, were most effective in raising per capita GDP growth, but that key policy related variables, including education, were essential ingredients contributing to per capita GDP growth. Evidence of mutual causality between private investment and growth, and inconclusive evidence regarding the incidence of FDI and infrastructure on private investment were also found in this chapter. 